\title{
Challenges Faced By Parent Due To the Presence of Mentally Handicapped Person in the Family
}

\author{
Dr. Meeta, Mukherjee ${ }^{1 *}$, Dr. Vijay, Shignapure ${ }^{2}$
}

\section{ABSTRACT}

Objective- The main purpose of the present study is to investigate that, to know the impact on family due to presence of mentally challenged child in the family. The presence of child with Mental retardation affects their social, emotional, economical, and psychological aspects. Research design- The present study used in the Survey research design. Method - The research design is scientific because it is based on empirical principles verifiability of data is possible in all stages of research process researcher strongly believes that through scientific verification of data could be able to test the hypotheses to derive cognate findings Result- The present study suggested that due to the presence of mentally challenged children in the family it affects their social, emotional economical and psychological aspects significantly. It has been observed that it disintegrates the family. Conclusion- The main purpose of the present study is investigated that, to know the impact on family due to presence of Mental retarded child in the family. The presence of child with Mental retardation affects their social, emotional, economical, and psychological aspects were affected in the mental retarded children.

Keywords: Mental Challenged, Family, Psychological, \& Socio-economic Status.

Parenting a Child is difficult and becomes much more taxing for parents when the Child happens to be one with a disability. A disabled child in the family calls for a lot of adjustment on the part of parents as well as other family members. The impact of disabled child on the parents and family has been well documented. Though they will always be individual difference in the reactions of each of the parents usually they are known to pass through a sequence of stages of reactions after knowing the diagnosis of disability in their child which is considered in fact to be quite normal (Evans, 1979; Cunningham, 1979; Honby, 1987). The first stages includes shock during which parents report feeling of confusion and happiness This is followed by denial stages during which parents are unable to accept that their child has disability or handicapped. They spend lot of time looking for a total cure. Parent also tend to feel sad and express anger when

\footnotetext{
${ }^{1}$ HOD, Aakanksha College of Special Education (MR), Raipur, Chhattisgarh, India.

${ }^{2}$ Associate Professor, Tirpude College of Social Work, Nagpur, Maharastra, India

*Responding Author

(C) 2016 I M Mukherjee, V Shignapure; licensee IJIP. This is an Open Access Research distributed under the terms of the Creative Commons Attribution License (http://creativecommons.org/licenses/by/2.0), which permits unrestricted use, distribution, and reproduction in any Medium, provided the original work is properly cited.
} 


\section{Challenges Faced By Parent Due To the Presence of Mentally Handicapped Person in the Family}

they find themselves helpless But when they reach adjustment stage, they start making efforts to do whatever possible and constructively contribute towards the development training and welfare of their child. Effective communication of diagnosis and need for imparting adequate information regarding the child's condition is the first important need of all parents (Peshawaria and Menon 1971).

Many parents complain that, "Had we been total about his condition honesty right in the beginning things would have been much better for us". Many a time professionals do not or are unable to give accurate information affectivity to the parents because of multiple reasons look of time, being ignorant of information communication barriers etc. Much of the parent's reactions, adjustment, attitudes and in involvement in the training of their child is going to depend on how sensitively this information is communicated.

Mentally retarded children often impose social restrictions on the family leisure activities. These restrictions gets compounded when there is a child with multiple disabilities, is severely retarded, has behavior problems, social isolation also increases as parents want to avoid feeling uncomfortable or hurt when asked question about the child's disability some parents are also reported to undergo mental difficulties factors contributing to it could be blamed each other for the condition of the child extra demands of caring, management of daily hassles or not being able to devote much time for each other because of fatigue and the exhaustion of caring for such a child.

However families are not always passive sufferers. They make efforts to overcome the difficulties and try to cope and adjust to this situation. In this situation certain things help them to cope like families need to gather the right kind of information about the condition and become knowledgeable about it. At some stage they have to accept the mental retardation in a family member and have hope that they will develop though in a slower pace. It is very important for families to preserve their own health maintain family cohesion and harmonious relations.

The World Health Organization (WHO) has defined the term impairment disability and handicap in 1980. Through the publication of the International Classification of Impairments Disability and Handicaps (ICIDH), in a manual of classification relating to the consequences of disease.

$$
\text { Disease }-\rightarrow \text { Impairment --> Disability } \rightarrow \text { handicap }
$$

Source: ICIDH Model (WHO 1980)

According to the ICIDH impairment is any loss or abnormality of psychological, physiological or anatomical structure or functions generally taken to be at organ level. Impairment is damage to tissue due to disease or trauma. A person who has poor or no vision due to the damage to retina or optic nerve may be said to have a visual impairment.

Disability has been defined by ICIDH as any restriction lack of ability (resulting from an impairment) to perform an activity in the manner or within the range considered normal for a 


\section{Challenges Faced By Parent Due To the Presence of Mentally Handicapped Person in the Family}

human being generally taken to be at the level of the individual. Disability denotes the consequence of impairment in terms of functional performance and activity by the individual.

Handicap, has been defined by ICIDH as a disadvantage for an individual resulting from an impairment or disability that limits or prevents fulfillment of a role that is normal (depending or age sex and social cultural factors) for that individual A handicap reflects the demands placed on the individual in a particular situation. An individual may indeed have a disability but may not have a handicap except in certain situation. The problems that a person faces as result of impairment and disability is called handicap, but a handicap is situation specific.

Defining disability is difficult to accommodate the expectation of all disabled groups. There are hundreds of different disabilities and there are as many causes for these disabilities. Some people are born with disabilities others become disabled later on in their lives some disabilities exhibit themselves only periodically like fits and seizures, others are constant conditions and are lifelong. Some disabilities can be controlled and cured while others still confuse the experts. Some include total or partial impairment of senses and physical and intellectual capabilities while defining disabilities. Others refer to a handicap or deviation of a social nature injuring or illness or incapacities to accomplish physiological functions or to obtain or keep employment. These definitions also reflect the consequences for the individual-cultural, social, economic and environmental-that stem from the disability.

\section{Mental Retardation:}

According to persons with Disability Act 1995 mental retardation means a condition of arrested means a condition of arrested or incomplete development of mind of a person which is specially characterized by sub normality of intelligence.

Locomotors Disability Berdine \& Black Hurst (1985) define on orthopedically disabled child as one whose physical or health problems result is an impairment of normal interaction with society to the extent that specialized services and programmer are required. Hallahan and Kauffmen (1991) define children with physical disabilities as those whose non sensory physical limitations or health problems interfere with school attendance or learning to such an extent that special services training, equipment, materials or facilities are required.

The PWD Act 1996 refers to orthopedic disability as locomotors disability and defines it as disability of the bones joints or muscles leading to substantial restriction of the movement of the limbs or any form of cerebral palsy. Along with its various categories of disabilities it is also very important to know its magnitude and extent of disabilities.

According to Sheeren Berger (1983) the elements of the definition of mental retardation were well accepted in the United States by 1990. These included on set in childhood significant in litterectual or cognitive limitation and an inability to adapt to the scheme proposed by the American Association on Mental Deficiency in 1910 referred to individual with mental 


\section{Challenges Faced By Parent Due To the Presence of Mentally Handicapped Person in the Family}

retardation an feeble minded meaning that their development was halted at an early age or was in some way inadequate making it difficult to keep pace with peers and manage their daily lives independently (Committee on Classification 1910). Over the next 30 years the definition of mental retardation on focused on one of three aspects of development the inability to learn to perform common acts deficits or delays in social development/competence or low IQ (Yepsen 1941).

Edgar Doll- proposed that mental retardation referred to social incompetence due to mental subnormality which has been developmentally arrested, which obtains at maturity is of constitutional origin and which is essentially incurable (Doll, 1936:.38). Ered Kuhlman- who was highly influential in the early development of intelligence tests in the United States believed mental retardation was a mental condition resulting from a subnormal rate of development of some or all mental function's (Kulhman 1941:9,213) As a results of the conflating views and definitions of mental retardation a growing number of labels used to refer to individuals with mental retardation. American Association on Mental Deficiency proposed and adopted three part definition in 1959. Mental retardation refers to sub average general intellectual functioning which originates in the developmental period and is associated with impairment in adaptive behavior (Heber 1961). This expression included three components of low I.Q.< 85, impaired adaptive behavior and origination before age 16 only I.Q. is measurable but difficult to know adaptive behavior of individual is a particular situation. In addition to the revised definition, a five level classification scheme was introduced replacing the previous 3 level scheme. The generic terms of borderline (IQ 67-83), mild (IQ-50-66), moderate (33-49), severe 16-32 and profound $<16$ were adopted.

Due to concern about the over or misidentification of mental retardation particularly in minority populations the definition was revised in 1973 (Grossman 1973) eliminating the borderline classification from the interpretation of significant, sub average general intellectual functioning. The upper IQ boundary changed from the $<85$ to $<70$. In 1977 revision, Gross man modified the upper limit to 70-75 to account for measurement error. The most recent change in the definition of mental retardation was adopted in 1992 by DSMIV attempts to blend the 1977 and 1992 definition put forth by AAMR. It adopts the 1992 definition but retains the severity level of classification scheme from the 1977 definition. The upper IQ limit is 70 and individual must have delays in at least two of the 10 areas outlined in the 1992 definition.

\section{REVIEW OF LITERATURE}

Existing studies reveals that very often the parents have a negative attitude towards their child with disabilities. The parents are plagued with feelings of pessimism, hostility and shame (Rangaswanri, 1995). Denials, projection of blame, guilt, grief, withdraw rejection and acceptances are the usual parental reactions (Drew, Logan, Hardman, 1984). Some person also experience helplessness feelings of inadequacy, anger, shock and guilt where others go through periods of disbelief, depression and self blame. The siblings also experience feelings of guilt, shame and embarrassment (Fred N, 1995). In India, disability is still viewed is terms of a 


\section{Challenges Faced By Parent Due To the Presence of Mentally Handicapped Person in the Family}

"tragedy" with a "better dead than disabled" approach the idea being that it is not possible for disabled people to be happy or enjoy good quality of life. Cultural beliefs about disability play an important role in determining the way in which family perceives disability and the kind of measures it takes for prevention, treatment and rehabilitation (Sen. A. 1988). Studies report that parental expectations from their disabled child were mostly negative and unrealistic.

Dalal and Panday investigated cultural beliefs and attitudes of a rural India community towards physical disability. The results revealed fatalistic attitude and external dependence in families with disabled children. In India there are strong beliefs in metaphysical causation. One of such belief in the theory of karma, which is often invoked to explain major life events including the occurrence of disability it has also been shown that people tend to accept their own disability as something which has resulted from their past karma or due to Gods will and thus often show low motivation to overcome the limitations (Berry \& Dalal, 1996). Any form of disability is looked upon as sins committed in their last birth. Studies reveal that this negative attitude adversely affects the family and parents. Family members of children with disability are often perceived to experience harmful psychological effects (Mc Cormack M, 1992).

Parents are often found with unstable emotionally constant grief, psychological ill-health, and unsatisfactory social health. Studies have found them to be at higher risk for marital discord and social Isolation. The commonest psychiatric disorder that was found is dysthymia followed by generalized anxiety disorder and moderate depression (Chandorkar \& Chakroborty, 2000). The majority of literature has highlighted stresses and the subsequent negative consequence in caring for a child with disability. In fact researchers have even proposed that when a child is diagnosed as having a severe disability the parents may experience similar cognitive processes to those individuals who have experienced a traumatic event (Turnbull and Turnbull).

\section{RATIONAL FOR THE STUDY}

Parents having a child with Mental retardation experience a variety of stressors and stress relations related to child's disability. Parents are known to get impacted in many ways including feeling sad, depressed, frustrated which pose problem in social adjustment and their functional abilities.

Marital harmony gets disturbed owing to various child related reason such as meeting extra childcare responsibilities and burden, affecting relationship between parents due to less privacy, more fatigue and fear of producing another child with disability.

The present research on the retardation is becoming bountiful, yet such increased efforts are not producing principles and techniques which substantially advanced new ways of dealing with this problem. The researches in this field had contributed to the widely accepted theory of psychological retardation and deviated from social and environmental factors. The psychological development consists of progressive changes in interaction between the individual as a pivotal 


\section{Challenges Faced By Parent Due To the Presence of Mentally Handicapped Person in the Family}

functioning biological system and the environmental events. The total environment is made up of effective stimuli from social and physical events outside of the body wall and from biological events in the organism. For retarded individual social, physical and biological conditions of development deviate in the direction of slowing down the pace of successive interactional changes - the more the curtailment of opportunities the more extreme the retardation.

\section{Research design-}

The present study used in the Survey research design.

\section{Method -}

The research design is scientific because it is based on empirical principles verifiability of data is possible in all stages of research process researcher strongly believes that through scientific verification of data could be able to test the hypotheses to derive cognate findings.

\section{Participants-}

In the present study the researcher had selected the Raipur district for this study from where had taken a sample of 240 respondents. Researcher had taken an adequate proportional and representative sample size for the study for this purpose through systematic random sampling the researcher selected 50 percent of respondents from urban area and 50 per cent from rural area and 50 parents from rural areas.

\section{Inclusion and exclusion criteria of the sample-}

The subject of the study is the family member of the mentally retarded so parents are the best source of information and mostly they handle and face the problem of dealing with their child so they are included as participants and other family members of this families and parents of mentally ill patients are excluded from participants

\section{Measure and methods of data collection-}

The Interview Schedule For Parent developed by Mukherjee and Shingnapure( 2006) was divided systematically to include various dimensions as aspects of the study, the questions were incorporated logically and language used was very simple and meaningful. The method of data collection was interviewing of the subjects of the study. The researcher personally contacted and interviewed the family members. Short observation schedule was initialized to include pertinent observation of the researcher about the community, which the family belongs to.

\section{Statistical Analysis-}

The present research qualitative and descriptive analysis is used in different items in variables treatment. After the collection of data, they were codified, edited and tabulated for the preparation of the tables, the independent and dependent variable were determined. 


\section{Challenges Faced By Parent Due To the Presence of Mentally Handicapped Person in the Family}

\section{RESULT \& DISCUSSION}

Mental retardation is a condition that not only has medical, educational and psychological implications, but has a major impact on the social system in any given community. We all know that mental retardation since ages was perceived differently by different communities ranging from calling them as "devil and evil spirit to good luck and God man incarnation.” It varies from culture to culture and also among persons with mental retardation. Because of their deviant behavior, they are at great risk of being devalued by the society, their low mental and physical capabilities fall below the expectation levels of society.

In our society considerable amount of ignorance and indifferent outlook exist regarding the concept of mental retardation. This is largely due to lack of or non-availability of proper information and guidance with regard to the causes, prevention, detection, management and facilities available for persons with mental retardation. Lack of awareness results in misconception, parents blaming themselves considering it as their karma, seeking the help of religious people, faith healers, going from doctor to doctor or looking for a magical cure for their mentally retarded is very common. There has been a lot of misconception and wrong practices seen across the society, no differentiation was made between mental illness and mental retardation as a result mentally retarded person have to suffer lot of ill-treatment in the society. Currently these two conditions have been recognized as separate entities.

The data for the study thus collected were processed, analyzed and interpreted with appropriate statistical methods for drawing the relevant inferences. The findings of the study are mainly drawn from the direct response of the respondents selected for the study.

i. $\quad$ A majority i.e. 30.4 percent of the respondents were in the age group of 42-47 years with the median age 44.5 .

ii. Maximum number of respondents i.e. 22.08 percent their monthly income was between Rs. 8001-11000.

iii. $\quad 94.5$ percent respondents were literate.

iv. Majority of respondents 22.3 percent have studied up to Graduation level.

v. More than 52.9 percent of respondents were engaged in service (Government and private sector)

Majority of the respondents that is 71.6 percent have number of children between $0-3$ in urban area but more than 4-5 in rural areas 
Feel their daily routine as well as their every aspect of life affected due to the presence of their disabled child

\begin{tabular}{|c|c|c|c|c|c|}
\hline \multirow[t]{2}{*}{ Daily routine } & & \multicolumn{3}{|c|}{$\begin{array}{l}\text { Presence of mentally } \\
\text { retarded child }\end{array}$} & \multirow[t]{2}{*}{ total } \\
\hline & & Always & sometime & never & \\
\hline \multirow[t]{2}{*}{ Always } & Count & 62 & 24 & 2 & 88 \\
\hline & Expected count & 34.5 & 44.0 & 9.5 & 88.0 \\
\hline \multirow[t]{2}{*}{ Sometime } & Count & 28 & 85 & 12 & 125 \\
\hline & Expected count & 49.0 & 62.5 & 13.5 & 125.0 \\
\hline \multirow[t]{2}{*}{ Never } & Count & 4 & 11 & 12 & 27 \\
\hline & Expected count & 10.6 & 13.5 & 2.9 & 27.0 \\
\hline \multirow[t]{2}{*}{ Total } & Count & 94 & 120 & 26 & 240 \\
\hline & Expected count & 94.0 & 120.0 & 26.0 & 240.0 \\
\hline
\end{tabular}

Chi-square test: 86.99 ; $\mathrm{df}=4$; contingency of coefficient $=.516$

The universal role of families is to nurture the young child. The families provide for the child's physical needs and foster the development of an integrated person capable of living in society and transmitting culture. Families with special needs face a number of obstacles in the efforts to help their handicapped child to get into society and to obtain needed resources. Thus the relationship between a retarded child and his family is not only more complex and ambivalent than the ordinary one but more intense and prolonged. (Manju Biswas1980) because the dependence of these children upon the family for the satisfaction of his needs is for lifetime.

Research in India has indicated that inability to perform social and household work satisfactorily in the family, interpersonal conflicts either between parents and other children, additional responsibilities, marital disharmony and social isolation were major inhibitors to effective coping (Moudgil, Kumar and Sharma 1985, Jain and Satyarthi 1969, Narayan 1979)

Holt (1957) studied two hundred and seven families with a subnormal child living at home in Sheffield found that 19 percent of mothers were exhausted by the physical work and emotional stress involved. Fathers were said to suffer to a lesser degree but marriages were strained by parental quarreling. Studies have mainly concentrated on time use among parents of children with disability and exclusively focused on direct child care activities. (Mcconachie1989, Stoneman Brody and Abrott 1983, Smith 1986). Although direct child care is certainly of great importance there has been little study of other categories of time use by fathers or children with disability.

Studies of families with a mentally handicapped indicate that when parents were not stressed the siblings were adapting well. Nevertheless, the adolescent normal sibling is reportedly at increased risk for stress. The risk is related to the burden of care on the family of raising a mentally retarded child (Grossman1972, Gath1974, Ruseman1981). 


\section{Challenges Faced By Parent Due To the Presence of Mentally Handicapped Person in the Family}

Fowle 1968 stated that resentment of added child care responsibility has been cited as a cause of tension between mothers and non-handicapped daughters.

Sometimes associated conditions of mentally retarded children also possess problem in caretaking. Some of the caretaking responsibilities varied depending on needs attributed to factors unrelated to an intellectual disability. Health concerns can impact on stress experienced by the parents. (Beckman 1983, Singer and Irvin, 1989)

A number of studies highlight that parents direct more than usual attention towards disabled children at the expense of time of their other children. (Begun 1989, Shulman1988)

Erickson Upshur (1989) conducted an exploratory study to see the difference between mothers of children with disability and without disability in their perception regarding child care taking and satisfaction with social support.The reports suggested that significant difference is seen in child caretaking, difficulty of feeding, bathing and dressing, caretaking time. Second finding was that fathers of infants with disability did not perform more caretaking tasks, than did fathers of infants without disability. Mothers of infants without disability were significantly less satisfied than mothers of infants with Disability"

The presence of disabled child restricts many families abilities to take part in everyday activities particularly out with their homes (Gath and Gumley 1987, Howlin1988, Frank Tatum and Tucker 1999).

The child with mentally retarded often imposes social restriction on the family (McAndrew 1976, Roas 1977, Wickler 1981).

The presence of the child with disability may also curtail the recreation needs of the family (Dunlop and Hollingsworth 1977, Londsale 1978).

Sethi and Sitholey (1986) reported parental burden in the form of interfaces in their family routine or leisure and recreation which even resulted in social, marital, familial and emotional problems in the home setting of individual with mental handicap.

Many professional referred to the strain on parents of caring for a disabled child as causing pressure, tiredness and frustration. In extreme situations this would lead to separation or divorce. One professional claimed family has split up due to continued strain and another said we often witness a breakdown in marriage.

Faber (1968) presents evidence of the adverse effect of mentally retarded child on marital integration, social activities, job promotion family roles and sibling occupational expectation.

In the following table the researcher has taken two variables for analysis both of them reveals the impact on family due to the presence of mentally handicapped child first variable is how the daily routine of family affected due their disabled child options are always, sometime and never and second variable is due to the child's presence parents feel that every aspect of their life has 


\section{Challenges Faced By Parent Due To the Presence of Mentally Handicapped Person in the Family}

been effected (career, health, marital, harmony, privacy, etc.) options are always, sometimes and never.

The above table depicts that 52 percent of respondents feel sometimes their daily routine has been affected due to the presence of their child, out of which 35.4 percent of respondent sometime realize that their life has been affected though not every aspect but some of the aspects like health, privacy, care taking etc. 11.6 percent feels that every aspect of their life has been affected due to the presence of their child.

5 percents never felt that anyway their life has been affected due to their child's presence they feel that even with the non disabled child they would have faced same problem because parenting is not easy job it requires patience, tolerance, understanding etc. to deal with them.

Next major category is 36.6 percent of respondents complained that they always feel that they are overburden due to their disabled child limiting their ability to engage in other activities of family, out of which 25.8 percent always full that their life has been affected because it is natural for parents to invest a great deal of time and energy into the child whose needs are more significant. Many a times mother has to sacrifice her promising career due to her disabled child, tired and frustrated fear of future make her vulnerable to health problems. In the last category 11.2 percent respondents never felt that anyway their daily routine has been hampered due to the presence of their child it may be due to mild and borderline mentally retarded children and even moderate child without behavior problems get well adjusted with their daily routine if they are properly trained. Out of which 5 percent never feel that this children are burden to them. On the contrary 4.5 percent always faced problem in their life feel burden to carry their responsibility 1.6 percent sometimes feels some aspect of their life has been affected

1. Further statistical analysis of the above table reveals that chi.sq. is 86.9 , $\mathrm{df}$ is 4 , cc. is .516 and probability; which shows that greater the care taking responsibilities of the child in day to day life for parents higher the feeling of the burden and their life seems to be affected.

2. Suggestion: 1. All families have strength and capacities that constitute resources which could be used to meet the need of others. The main theme calls our attention to the strengths of special needs families rather than counting the deficits. It is the best way of empowering special needs families.

3. People who believe that they can control what happens to them in life are not likely to persist inspite of the difficulties and may be less likely to be affected by stress.

4. Social support or self help groups have been increasingly popular forms of family support among families who have children with disabilities.

Support groups may be organized by professionals (social worker) or may arise informally through association among family members. Family members who meet other parents in similar situations have opportunities to make comparison with other children and to share experiences 


\section{Challenges Faced By Parent Due To the Presence of Mentally Handicapped Person in the Family}

with parents and professional. These support groups may help to achieve a mastery or control over the situation.

Parents Feel Their Parenthood Negative and They Are Different Parent with the Presence of Mental Retarded Child

\begin{tabular}{|c|c|c|c|c|c|}
\hline \multirow{2}{*}{$\begin{array}{l}\text { Feel } \\
\text { Different }\end{array}$} & & \multicolumn{3}{|c|}{ Parenthood negative } & \multirow[t]{2}{*}{ Total } \\
\hline & & Very much & More or less & Nat at all & \\
\hline \multirow[t]{3}{*}{ Always } & Count & 8 & 10 & 0 & 18 \\
\hline & $\begin{array}{l}\text { Expected } \\
\text { count }\end{array}$ & 2.9 & 8.2 & 6.9 & 18.0 \\
\hline & $\begin{array}{l}\text { \% within feel } \\
\text { as different } \\
\text { parent }\end{array}$ & $44.4 \%$ & $55.6 \%$ & $.0 \%$ & $100.0 \%$ \\
\hline \multirow[t]{3}{*}{ Sometime } & Count & 28 & 75 & 19 & 122 \\
\hline & $\begin{array}{l}\text { Expected } \\
\text { count }\end{array}$ & 19.8 & 55.4 & 46.8 & 122.0 \\
\hline & $\begin{array}{l}\text { \% within feel } \\
\text { as different } \\
\text { parent }\end{array}$ & $23.0 \%$ & $61.5 \%$ & $15.6 \%$ & $100.0 \%$ \\
\hline \multirow[t]{3}{*}{ Not at all } & Count & 3 & 24 & 73 & 100 \\
\hline & $\begin{array}{l}\text { Expected } \\
\text { count }\end{array}$ & 16.3 & 45.4 & 38.3 & 100.0 \\
\hline & $\begin{array}{l}\text { \% within feel } \\
\text { as different } \\
\text { parent }\end{array}$ & $3.0 \%$ & $24.0 \%$ & $73.0 \%$ & $100.0 \%$ \\
\hline \multirow[t]{3}{*}{ total } & Count & 39 & 109 & 92 & 240 \\
\hline & $\begin{array}{l}\text { Expected } \\
\text { count }\end{array}$ & 39.0 & 109.0 & 92.0 & 240.0 \\
\hline & $\begin{array}{l}\text { \% within feel } \\
\text { as different } \\
\text { parents }\end{array}$ & $16.3 \%$ & $45.4 \%$ & $38.3 \%$ & $100.0 \%$ \\
\hline
\end{tabular}

\section{Chi-Square test: Chi-square $=95.151 ; \mathrm{df}=4$; Contingency Coefficient $=.533$}

The parent of mentally handicapped child feels that the handicapped child is the living grave of their hope for a normal baby. (Goldie 1966) It is as if the child they knew had died and a strange child had been left in his place. Sometimes parents blame themselves for the disability. They feel it is a result of something they did on did not do or they feel they should have recognized the problem sooner. (Alvin Eden MD). Society views the parenthood positively but it views parenthood of a handicapped child negatively. (Zuk, 1962) The stigma of the handicapped 


\section{Challenges Faced By Parent Due To the Presence of Mentally Handicapped Person in the Family}

person is one of shame and inferiority. (Wright, 1960) which marks the person as tinted and discounted. For many handicapped individuals and their families the most devastating consequence of being handicapped are often not the direct physical or mental results of impairment itself, but rather the attitudes and reactions of those in the society who are not handicapped

Mostly the parents of children with mental retardation are subject to stigma. Most communities or neighborhood members are not exposed to or educated about individuals with mental retardation (Kazak and Wilcox 1984). Further, the general public has low tolerance for behavior outside of the norm. Families of children with mental retardation are often sensitive to drawing negative attention to their families in public places. (Moudgil et al, 1985) found that because of mentally retarded child in the family parents feel depressed most of the time, worry about getting their children admitted to school, have to pay more attention to retarded child, and their marital harmony and relations with their family member are disturbed. The social image of the parents is also affected. Several theoretical formulations about parenting. (Belsky, 1984, Cohen \& Weissman 1984 Wahler and Dumas 1986) concur that the marital relation is an important contextual factor that effect the parenting experience.

Parents who report a positive family experience also report a positive view of their child with a disability. They focus on their child's strengths, not on their limitations. They recognize their potential for growth and encourage his or her development. One study found that family coping well with a special needs child maintain a positive attitude have realistic expectations of their child and are less preoccupied with negative thoughts.(Yau\&LiTsang, 1999). At the same time however several theorists (Benson \&Gross 1989, Byrne\& Cunningham 1985, Crnic, Friedrich\& Greenberg 1983) stress the importance of individual adaptation, and speculate that great variability in adjustment occurs for individual families based in part on both the functions of child and competencies and resources the parents bring to their role as caretaker.

\section{ANALYSIS OF TABLE}

The above table indicates that majority of the respondents (75) 61.5\% sometimes feel that they are different parent due to the presence of their handicapped child and also expressed more or less they think that parenthood of handicapped child as negative. Next majority of respondents (73) $73 \%$ neither feel that they are different parent nor they think that their parenthood as negative. They hold positive feelings as they are aware and conscious parents and never view parenthood as negative. Next category of respondents (55.6\%) always report that they are different parent and with their handicapped child they view more or less their parenthood negative. The table further reveals the fact that (8) $44.4 \%$ of respondents experienced that while moving in the society they have the deep feeling that they are different due to their child and very much view their parenthood as negative. On the contrary only $24 \%$ respondents said that they not at all think they are different from others but sometimes more or less down with negative feeling as parent. 23\% respondents sometimes feel different parent but never view their parenthood negative. 


\section{Challenges Faced By Parent Due To the Presence of Mentally Handicapped Person in the Family}

The analysis of above table depicts the fact that most of the parents seems to have accepted the disability in general and their child's condition in particular and reported that they don't feel different parent due to their child because of this positive feeling they don't view their parenthood negative.

Certain factors such as illness, death, poverty, marriage problems and disability can all affect the development of such a positive relation between parents and children. Pregnancy, a period also named as 'expecting', coincides with the expectancy of a healthy baby. Therefore, the experience of having a disabled baby yields the parental loss of the imagined 'normal' child and the subsequent struggles to establish a new set of expectations, feelings and way of life (Weisner et al., 1991). Different writers have expressed the nature of parenting to become 'hardship' (McConachie, 1991), 'uncertain future' (Stallard and Dickinson, 1994), and frequently experienced feelings to be pain, shame, guilt, pity, anger, revulsion, disappointment, frustration and many more to come over the years (Akkök, 1994, Mittler, 1994; Sinason, 1993; Weisner et al., 1991). Stressing the importance of searching for benefits in rearing such children will become a valuable resource both for fieldworkers and parents in the long run (Clayton et al., 1995).

SUGGESTIONS With times families can move past merely accepting their situation and begin to appreciate its positive aspects (SANDLER \&Mistretta) when they share the positives with other families they can strengthen and encourage themselves and others Many parents see this child as a divine son or daughter of god and feel it a blessings to be entrusted with a special needs child (Olson, Dollahite \& White 2002).

Parents feel to commit suicide and feel about others attitude towards their child

\begin{tabular}{|l|l|l|l|l|l|}
\hline \multirow{3}{*}{ Committing suicide } & & \multicolumn{3}{l}{ Worried about others } & \multirow{2}{*}{ Total } \\
\cline { 3 - 5 } & & $\begin{array}{l}\text { Very } \\
\text { much }\end{array}$ & $\begin{array}{l}\text { To some } \\
\text { extent }\end{array}$ & $\begin{array}{l}\text { Not at } \\
\text { all }\end{array}$ & \\
\hline \multirow{2}{*}{ Frequently } & Count & 6 & 2 & 0 & 8 \\
\cline { 2 - 5 } & Expected count & 3.2 & 4.1 & .7 & 8.0 \\
\hline \multirow{2}{*}{ Occasionally } & Count & 26 & 11 & 1 & 38 \\
\cline { 2 - 5 } & Expected count & 15.0 & 19.6 & 3.3 & 38.0 \\
\hline \multirow{2}{*}{ Never } & Count & 63 & 111 & 20 & 194 \\
\cline { 2 - 5 } & Expected count & 76.8 & 100.2 & 17.0 & 194.0 \\
\hline \multirow{2}{*}{ total } & Count & 95 & 124 & 21 & 240 \\
\cline { 2 - 5 } & Expected count & 95.0 & 124.0 & 21.0 & 240.0 \\
\hline
\end{tabular}

Chi-square test $=21.91 ; \mathrm{df}=4$; coefficient of contingency $=.289$

Today's parents face a world of challenges with everything from keeping themselves healthy and happy to providing their children a safe environment that fosters the physical and emotional and social growth of their children in today's society. Sometimes the everyday demand of life seems too great to overcome and families will experience stress and or crisis as they try to survive. And 


\section{Challenges Faced By Parent Due To the Presence of Mentally Handicapped Person in the Family}

having a child with disability can drive families apart or into a state of chronic stress where parents may feel to commit suicide in rage of disappointment (by C. Amber Havens) .

Wolf et al 1989 suggested that there are many potentially threatening events and life circumstances that arise in the family due to the child's disability.

Suicide is from Sui (casdere to kill oneself.) Suicide can also refer to an individual who has killed him or herself. Suicide may have psychological origins such as the difficulty of coping with depression or other mental disorder. It may also stem from social and cultural pressures. Depression however is a common phenomenon amongst those who commit suicide. (Encyclopedia of Mental health) Individual under these stress become anxious and depressed and then usually in reaction to a particular crisis they attempt to harm themselves.

Retarded people live in an atmosphere created by the attitudes held by the people and professionals they come in contact with an addition to those of their families.

By and large all the sections of society will not accept these persons into the mainstream. Especially in a developing country like India, many misconceptions and wrong practices are due to their negative attitude lack of understanding and lack of encouragement. Families who have a member with a disability have long been objects of pity.

Society on a whole tends to view the presence of a child with a disability as an unutterable tragedy from which the family may never recover. Thus according to Goffman (1961) these stereotypes reflect societal attitudes about the negative and valueless aspects of individuals with disabilities, Therefore, stereotypes from the literature that have impacted intervention strategies strategies have likely reflected societal values (Summers et al, 1989). An underlying assumption among professionals that "children without disability are a burden easy to raise and children with disability are a burden (Turnbull and Turnbull, 1986) further reflect this perceptions. These professionals have learned how to deal with crisis but not how to deal with crisis but not how to deal with coping in families of children with disability (Long and Bond, 1984, Summers et al 1989, Trute and Hauch, 1988).

The biases have inherently caused stress to families due to interactions shaped by these negative attitudes (Summers et al, 1989). Therefore, distress is not always produced by the child with a disability but may emanate from societal perceptions (Bronfenbenner, 1979.)

In the following table the investigator has taken two variables first parents thought of committing suicide in which options are frequently, occasionally and never and second variable is parents are worried about others attitude towards their disabled children which is categorized as very much, to some extent, not at all.

The above table clearly indicates that 80.83 percent of respondents never felt to commit suicide because of their child which reveals that parents don't feel this problem as serious or fatal to take such as drastic step like committing suicide because they have faith and believe that sooner or 


\section{Challenges Faced By Parent Due To the Presence of Mentally Handicapped Person in the Family}

later the child would start functioning normally this because of excessive hopelessness of their child's condition out of which 46.23 percent were worried to some extent about the attitudes of other 26.2 percent very much worried about others attitude only 0.8 percent not at all worried.

In the next major category comes 15.8 percent respondent who occasionally felt to commit suicide here the investigator observed that the child's disability is not directly affected the parents but the circumstances which occurred due to child's disability like financial burden, father deserted the family due to child's disability, marital unhappiness, societies attitudes etc. Out of which 10.8 percent are very much worried about others attitude, 4.5 percent to some extent get worried.

These parents are worried about others attitude because friends and family members may not understand the special needs of a child with mental retardation and thus may not be able to provide any support, another problem which these parents face is interference and over involvement of neighbors and relatives who gives suggestion to parents of managing the child with mental retardation and other systematic training leave parents often very confused. In the last category only 3.3 percent which is very nominal percent of respondents felt to commit suicide which indicates that in some cases due to severity of disabled child, parents feel sensitive to drawing negative attention to their families in public places, burden of carrying daily routine of these children very tiresome or mothers being blamed for this child's condition and foremost is the fear of future of this child. Out of which $2.5 \%$ feel worried about others attitude, $0.8 \%$ to some extent are worried about other attitude towards their children.

These studies have indicated that families have tremendous resiliency and can mobilize resources to cope with their particular challenges.

The statistical data shows the significant relationship between the two variables chi-sq.is 21.91, df is 4 and c.c is .289 prob. 9.48 .

It is to be suggested that family centered practice is more helpful than child centered intervention. Family involvement in the treatment and education process leads to a greater sense of empowerment and family satisfaction. Family wants to be part of treatment and evaluation. All of these strategies that work with families will require extensive field training for community based practitioners. Suicide prevention counseling in valuable tool for public health, A wide variety of health professionals including social workers can be taught to help people with suicide prevention counseling techniques. These services can be provided in wide variety of places and settings.

\section{CONCLUSION}

Children and family for last 21 years I learned that not always it is the child's disability that disintegrates family but as parent react to the problem. 


\section{Challenges Faced By Parent Due To the Presence of Mentally Handicapped Person in the Family}

Parents find it difficult to face mostly negative attitude of society and stigma attached to it. This existing negative attitude of parents as they are plagued with feeling of pessimism, hostility and shame inspired me to select this topic to know and examine their reasons. There is need to understand various issues concerning mentally retarded children and their families at various levels to ensure sustainable, equitable and development of children with mentally handicapped from social work point of view. Besides this, the present study can develop certain theoretical structures in Social Sciences especially related to disability field, social work education and rehabilitation sciences.

Findings of the proposed study are of great value to Universities, Govt. of India, Govt. of state of Maharashtra and Chhattisgarh and other agencies. The researcher believes that the present study can contribute towards theory building in social work as well as development of methods of social work skills and attitudes.

\section{REFERENCES}

Berdine and Black Hunst 1985

Berry, J. \& Dalal, A. K. (1996). Disability Attitudes, Beliefs, Behavior: A preliminary report on an International project in Community Based Rehabilitation unpublished manuscript, ICA, CBR Queen’s university, Kingston, Canada.

Chandokar. H. \&, Chakraborty, P. K. (2000). Psychological Morbidity of parents of mentally retarded children. Indian Journal of Psychiatry, 42, 271-274.

Doll. E. A. (1953). The measurement of social competence A manual for the vineland social maturity scale Washinton DC Educational test Burea Drew C.J, Logan, ESCAP Population Data sheet 2001 (Bangkok).

Drew, C. J, Logan., D. R. \& Hardiman, M. L.(1984). Mental Retardation - A life style approachToronto : Times/ mirror/ mostle college Publishing House.

Evans, E. C. (1979). The grief reaction of parents of the retarded and counselors role Australian Journal of mental retardation 4, 8-12.

Freud.N 1995

Goffman, E.( 1961). Stigma Englewood cliffs,; N.J. Prentice Hall. Asylums garden city. N.Y. Double day and Company.

Herber, R. A. (1961). A manual on terminology and classification in mental retardation (2 ${ }^{\text {nd }}$ ED) Monograph supplement to the American Journal of Mental Deficiency.

Keily, M. (1987). The Prevalence of Mental Retardation Epidmiologic reviews, 9:194-218.

Kirk S.A \& Gallagher (1989). educating exceptional children $\left(6^{\text {th }}\right.$ Ed) Boston, Houghton, Mifflin

Kuhlman. F, McCubbin, H. I., \& Patterson J. M. (1983). The family stress process; The double ABCX model of family adjustment and adaptation, Marriage and family Review, 6-7-37.

Minnes, P. (1988a). Family stress associated with developmental handicapped child. American Journal of Mental Retardation, 93, 184-192.

Peshawaria, R. \& Menon D.K. (1992). Working with families of children with mental retardation in India: various Models. 
Rangaswami, K. (1995). Parental attitude towards Mentallt Retarded children. Indian Journal of Clinical Psychology, 22, 20-23.

Sen, A. (1988). Psychological Integration of the handicapped. New Delhi: Mittal Publication. Sheerenbeeger, R. C. (1983). A history of Mental Retardation Baltimore. Brokes Publishing Co. Turnbull \& Turnbull, H. R. (1986). Family function in families, professional and exceptionally: A special partnership Columbus OH: Merrill 198614. pg.11.

Yepsen.L. 1941

\section{Acknowledgement}

The research is the product of collective culmination of the efforts of many experts it is a team work process. I would like to express my gratitude to all those who gave me the possibility to complete this paper I am deeply indebted to my supervisor Dr. Vijay. J. Shingnapure Reader Nagpur University who was always there to listen and give advice stimulating suggestions and encouragement. My special thanks to my colleague Mr. Gaukaran Janghel , faculty in Aakanksha. Last but not least my grateful acknowledgement and special salute to my elder daughter Ms PIYALI who showed me the new path which was less traveled by others and find ability in disability. Her favorite slogan“ Hum Honge Kamyab Ek Din” 